\title{
Manpower Planning with Annualized Hours Flexibility: A Fuzzy Mathematical Programming Approach
}

\author{
Md. Gulzarul Hasan*, S. Suhaib Hasan*
}

\begin{abstract}
We have considered the problem of annualized hours (AH) in workforce management. $\mathrm{AH}$ is a method of distributing working hours with respect to the demand over a year. In this paper, the basic Manpower planning problem with $\mathrm{AH}$ flexibility is formulated as a fuzzy mathematical programming problem with flexible constraints. Three models of the AH planning problem under conditions of fuzzy uncertainty are presented using different aggregation operators. These fuzzy models soften the rigidity of the deterministic model by relaxing some constraints with the use of flexible programming. Finally, an illustration is given with a computational experiment performed on a realistic-scale case problem of an automobile company to demonstrate and analyze the effectiveness of the fuzzy approach over a deterministic model.
\end{abstract}

Keywords: annualized hours, fuzzy mathematical programming, manpower planning, workforce management, flexible working

Mathematics Subject Classification: 90B70, 90C70

Submitted: October 29, 2016

Revised: June 22, 2017

\section{INTRODUCTION}

Workforce management is an important aspect for every industry. One of the major reasons for its need is the variation in the demand for skilled workers as well as their availability throughout the year. The variation in demand may be due to seasonal effects, whereas the variation in workforce availability may be due to illness, training, vacation, etc. As high demand leads to hectic overtime and lower demand leads to the underutilization of the workforce, there is a need for proper management. The annualized hours policy is one of the methods that helps an organization to efficiently match workforce demand and it's availability over the year. Also, it is as used in the

* Aligarh Muslim University, Department of Statistics and Operations Research, Aligarh, India, e-mail: gulzarhsn@gmail.com 
labor legislation of countries like France (Grabot and Letouzey, 2000), Britain (Rodriguez, 2003), and the Netherlands (Van den Hurk, 2007). It gives greater flexibility by distributing the working hours of the hired workforce over the year to fulfill the fluctuation of demand. The greater advantage of the annualized hours policy is that it leads to a reduction in overtime and the underutilization of the workforce. It also reduces total cost, limits the need for part-time workers, and gives an improved service level. It gives fruitful results in labor intensive industries for e.g. Filho and Marcola (2001) reduces overtime by $94 \%$ and the use of temporary workers by $53 \%$. A reduction in temporary workers results in an improved service level. According to Thomas Sanderson (Workforce logistics, 2016), productivity increases by $25 \%$, and labor costs reduced from the previous year. Also, McMeekin (1995) showed that stock levels had reduced to a large extent because of the implementation of the AH policy in Tesco distribution.

In this paper, we integrated the annualized hours planning problem (AHPP) to a concept of uncertainty; i.e., fuzziness. Since the AHPP is a real-life problem (and in real life, things are not certain), it motivates us to work on the uncertainty factors of the AHP problem. The concept of fuzzy makes the AHPP more real. Multitasking workers with respective relative efficiency is considered. We determine the shortage of workforce for each task and optimize the service level by minimizing the relative shortage of capacity and demand for workers.

\section{LITERATURE REVIEW}

Annualized hours planning (AHP) problems have been well-studied by many authors. Some of them are Azmat and Widmer (2004), Azmat et al. (2004), Corominas et al. (2002, 2004, 2007a, 2007b, 2012), Hertz et al. (2010), Van der Veen et al. (2014), and Filho and Marcola (2001).

In the AH problem, workforce demand is in terms of hours, but some authors also considered demand in the form of shifts; e.g., Azmat and Widmer (2004), Azmat et al. (2004), Hung (1999a), Hung (1999b). Some also considered skills; e.g., Corominas and Pastor (2010), Corominas et al. (2002), Corominas et al. (2005), Grabot and Letouzey (2000), and Lusa et al. (2008b).

Annualized hours planning with single and multiple contracts is also considered by some authors, where workers are contracted for the same or different working hours. Multiple employee contract types have been considered by Hertz et al. (2010), Lusa et al. (2008a), and Lusa et al. (2008b). Mathematical programming is the most-used-solution method for AHP problems. Campbell and Diaby (2002) and Corominas and Pastor (2000) propose a three-phase method. Hung (1999a) and Hung (1999b) uses algorithms for variants of the AHPP. Furthermore, a cross entropy optimization method is proposed in Van der Veen et al. (2012). Scenario-based Multistage stochastic optimization was applied by Lusa et al. (2008a).

Many authors worked with deterministic demand, like Azmat and Widmer (2004), Azmat et al. (2004), Hung (1999a), Hung (1999b), Sureshkumar and Pillai (2012), Sureshkumar and Pillai (2013), and Van der Veen et al. (2014), and stochastic demand is assumed in Lusa and Pastor (2011). In the real world, demand is uncertain and cannot be precisely known. 
Zimmermann (1996) categorized uncertainty as stochastic uncertainty and fuzziness. Stochastic uncertainty occurs with the randomness of an event, while fuzzy uncertainty appears when the information is vague, imprecise, or ambiguous, or when the information is not clearly defined. The concept of fuzzy set theory was first introduced by Zadeh (1965) and has been found in extensive applications in different fields, like operations research, control theory, management science, artificial intelligence, etc. In 1970, Bellmann and Zadeh (1970) developed a decision theory in a fuzzy environment.

In mathematical programming, fuzzy mathematical programming (FMP) deals with fuzzy uncertainty. The fuzziness can appear in different forms; i.e. in inequalities, objective function and parameters. Fuzzy mathematical programming is further categorized as flexible programming, possibilistic programming, and robust programming; see Cadenas and Verdegay (2006) and Jiafu et al. (2004). Flexible programming is applied when there is vagueness, the possibilistic approach is used when there is ambiguity, and robust programming is applied when vagueness and ambiguity both occur simultaneously. Here in our Fuzzy Model of the AHPP, we are using the flexible programming approach. Applications of the flexible programming approach can be found in Itoh et al. (2003), Lai and Hwang (1992), Miller et al. (1997), Pendharkar (1997), Rabbani et al. (2012), and Selim and Ozkarahan (2008).

Previously, Ull Hasan et al. (2015) applied the concept of fuzzy in the AHPP, providing an optimum schedule of workers while minimizing the annual overtime cost. In this paper, we minimize the capacity shortage in the AHPP, where some of the parameters are assumed to be uncertain in the form of fuzziness and solved using fuzzy mathematical programming (FMP) approaches.

The layout of this paper is as follows: Section 2 discusses related literature; in Section 3, we give the basic model of a deterministic AHPP; Section 4 describes the fuzzy models of the AHPP and a solution approach; Section 5 is about experimental study for the deterministic and fuzzy models of the AHPP; finally, Section 6 presents the conclusion.

\section{PROBLEM FORMULATION}

In this paper, we are working on a basic model of the $\mathrm{AH}$ planning problem and optimizing the service level by taking into account the working efficiency of workers. No holiday nor temporary workers are considered. Overtime is allowed with an upper bound. It is assumed that there are different types of tasks and that the company forecasts demand and establishes the capacity requirement. As overtime is bounded, capacity shortage is possible during certain weeks. Cross-trained workers are considered to have different relative efficiency (RE) (a scale of 1) associated to them (e.g., a value of 0.6 means that such a worker needs to work (1/0.6) hours to perform a task that a worker with RE equal to 1 would perform in 1 hour). The French 35-hour law [see Official site (2016) and Wikipedia (2016)] is applied to make the model more real; the number of weekly working hours falls within an interval with upper and lower bounds. Also, the total working hours for the planning period also fall within a certain interval.

The problem studied and modeled in this paper is based upon the minimization of the relative shortage of capacity with respect to demand on the workforce. Since 
a high relative capacity shortage leads to a worse service level, the objective of the problem is to minimize the weighted sum of the maximum relative capacity shortage and the sum of the weekly relative capacity shortages.

The characteristics of the problem are as follows:

1) Planning period of the allocation of workforce is taken as 52 weeks (i.e., 1 year).

2) No holiday week is considered in this problem.

3) Working hours for each week and year is lower and upper bounded.

4) Different types of tasks with forecasted demand are taken with the assumption that the staff is multitasking, having different relative efficiency associated to them.

5) Overtime is permitted with an upper bound.

6) Hiring temporary workers is not allowed.

7) The average number of working hours for a group of 12 consecutive weeks cannot be more than 44 hours per week.

8) A utility function is to be optimized.

The list of notations which will be used throughout the paper is given below.

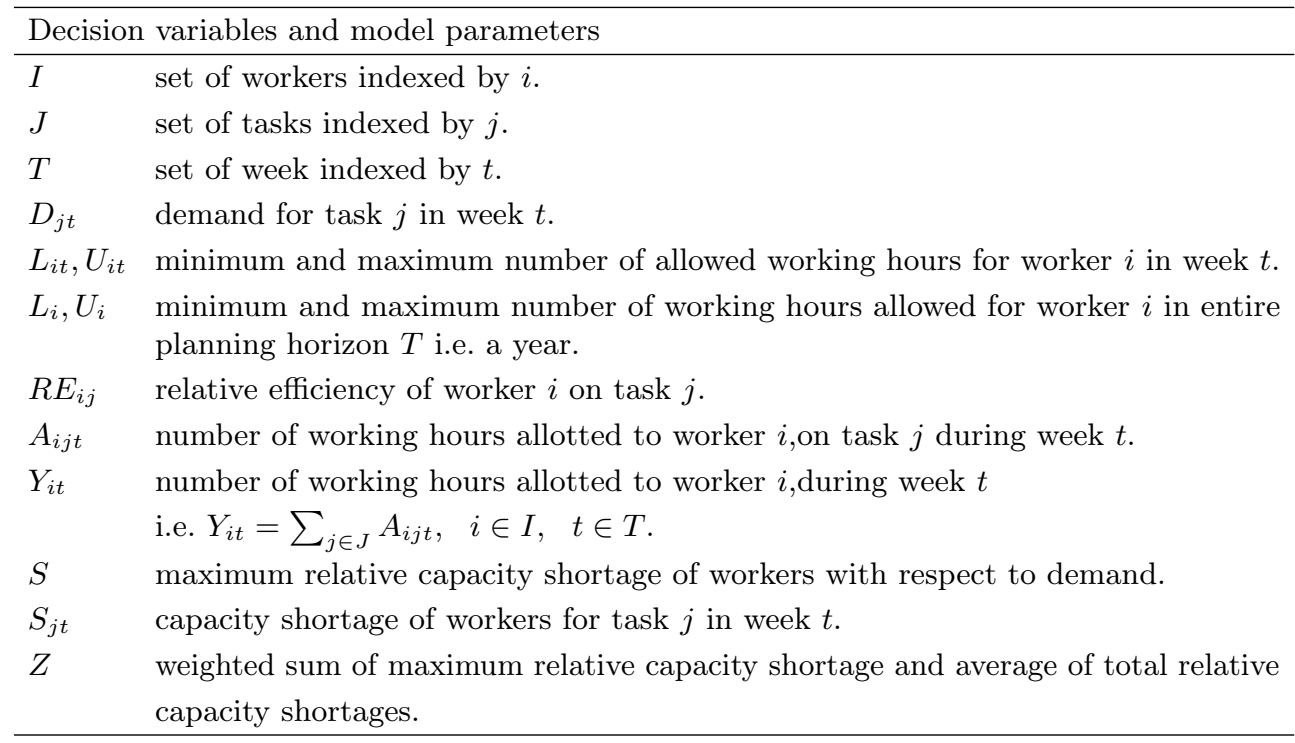

The basic mathematical model of the above-explained problem with deterministic data is as follows:

$$
\operatorname{Min}: Z=\alpha \cdot S+\beta \cdot \sum_{j \in J} \sum_{t \in T} \frac{S_{j t}}{D_{j t}}
$$

Subject to,

$$
\begin{gathered}
S \geqslant \frac{S_{j t}}{D_{j t}} \forall j \in J, t \in T \\
L_{i} \leqslant \sum_{t \in T} Y_{i t} \leqslant U_{i} \quad \forall i \in I
\end{gathered}
$$




$$
\begin{gathered}
L_{i t} \leqslant Y_{i t} \leqslant U_{i t} \quad \forall i \in I, t \in T \\
\sum_{i \in I} R E_{i j} \cdot A_{i j t}+S_{j t} \geqslant D_{j t} \quad \forall j \in J, t \in T \\
\sum_{t=m-K+1}^{j} Y_{i t} \leqslant h_{K} \cdot K \quad \forall i \in I, m=K \ldots T \\
Y_{i t} \geqslant 0 \text { and } \forall i \in I, t \in T \\
A_{i j t} \geqslant 0 \quad \forall i \in I, j \in J, t \in T
\end{gathered}
$$

The objective function (1) is the weighted sum of the maximum relative capacity shortage and the sum of the weekly relative capacity shortage with associated weights alpha and beta. Constraint (2) ensures that the maximum relative capacity shortage is greater than the weekly relative capacity shortages for all tasks. Inequality (3) defines bounds of the annual sum of weekly working hours to be allotted to each worker and inequality (4) bounds of weekly working hours to be allotted to each worker. Constraint (5) ensures that the number of working hours allotted to the workers for each task and for each week added to the shortage hours is greater or equal to the forecasted demand. Constraint (6) imposes an upper bound on the average weekly working hours for any consecutive $K$ working weeks. (7) and (8) define non negativity constraints.

\section{UNCERTAINTY MODELING}

The AHPP basic model is a mathematical programming model with deterministic data. Certainty is assumed in all aspects of the problem. In real life, we often deal with uncertainty instead of certainty. The deterministic model provides rigidity; so, a new model is presented with the assumption of uncertainty in the form of fuzziness. A fuzzy mathematical programming approach is applied to overcome the rigidity of the deterministic model.

In the AHPP, the forecasted demand of working hours can never be deterministic. In real life, demand can never be predicted certainly; hence, the demand constraint is fuzzified. Also, the minimum number of contracted working hours by each worker for the whole year is fixed. But in real life, contracted hours are not always fulfilled because of leaves, illnesses, training, etc. (which makes its nature fuzzy). The upper limit on the annual working hours for each worker is also fuzzified, giving more flexibility to work overtime.

The relative capacity shortage and objective function also changed their character from deterministic to fuzzy because of the presence of fuzzy demand. We want the goal to reach some aspiration level of the objective function.

Hence, the appearance of uncertainty in the form of fuzziness transforms the deterministic AHPP model to a fuzzy AHPP model. The Fuzzy-AHPP is modeled based on Zimmermann's (1976) approach to dealing with fuzzy inequalities, where the membership function assumed is linear. 
As by Tsai et al. (1997), the advantage of Zimmermann's (1976) approach over other methods is that different combinations of membership functions and aggregate operators can be used, which results in linear models.

According to the Bellman and Zadeh (1970) approach, the optimal solution of a problem is such a solution of the problem that simultaneously fulfills the constraints and goals to a maximal degree. The decision-maker can establish an aspiration level for the value of the objective function. In FMP, fuzzy operators are used to transform FMP to traditional mathematical programming. In this research, three types of aggregators have been applied; namely, the "max-min-operator" (Bellman and Zadeh, 1970), "convex combination of min-operator and max-operator" (Zimmermann, 1996), and "fuzzy-and operator" (Werner, 1987).

\section{Fuzzy AH planning problem model (FAHPP)}

In this section, the fuzzy AHPP model is presented.

$$
\begin{gathered}
\alpha \cdot S+\beta \cdot \sum_{j \in J} \sum_{t \in T} \frac{S_{j t}}{D_{j t}} \lesssim Z_{1} \\
S \geqslant \frac{S_{j t}}{D_{j t}} \forall j \in J, t \in T \\
\sum_{t \in T} Y_{i t} \lesssim U_{i} \quad \forall i \in I \\
-\sum_{t \in T} Y_{i t} \lesssim-L_{i} \quad \forall i \in I \\
L_{i t} \leqslant Y_{i t} \leqslant U_{i t} \forall i \in I, t \in T \\
-\sum_{i \in I} R E_{i j} \cdot A_{i j t}-S_{j t} \lesssim-D_{j t} \forall j \in J, t \in T \\
\sum_{t=m-K+1}^{j} Y_{i t} \leqslant h_{K} \cdot K \quad \forall i \in I, m=K \ldots T \\
Y_{i t} \geqslant 0 \text { and } \forall i \in I, t \in T \\
A_{i j t} \geqslant 0 \quad \forall i \in I, j \in J, t \in T
\end{gathered}
$$

The symbol $\lesssim$ represents fuzzy inequality and means "essentially less than or similar to". These fuzzy constraints show that the decision-maker wants to make the left-hand side of the constraints smaller or similar to the right-hand side "if it is possible".

In the above fuzzy AHPP model from equation (9)-(17), uncertainty is assumed in the objective function, the lower and upper bounds of the annual working-hour constraint, and the demand constraint. In our study, we consider a monotonically increasing or decreasing linear membership function for these fuzzy characters (for the sake of convenience). Therefore, the relevant membership function and its graphical illustrations in Figures 1, 2, 3, and 4 are presented below. 
Membership function for objective function

$$
\mu_{Z}(x)= \begin{cases}1 & \text { if } Z \leqslant Z_{1} \\ 1+\frac{Z_{1}-Z}{P_{0}} & \text { if } Z_{1}<Z \leqslant Z_{1}+P_{0} \\ 0 & \text { if } Z_{1}+P_{0}<Z\end{cases}
$$

where $Z=\alpha \cdot S+\beta \cdot \sum_{j \in J} \sum_{t \in T} \frac{S_{j t}}{D_{j t}}$.

An aspiration level $Z_{1}$ is established by the decision-maker for the objective function that is to be achieved and $P_{0}$ is the tolerance level that the decision-maker can tolerate in the accomplishment of the fuzzy constraint.

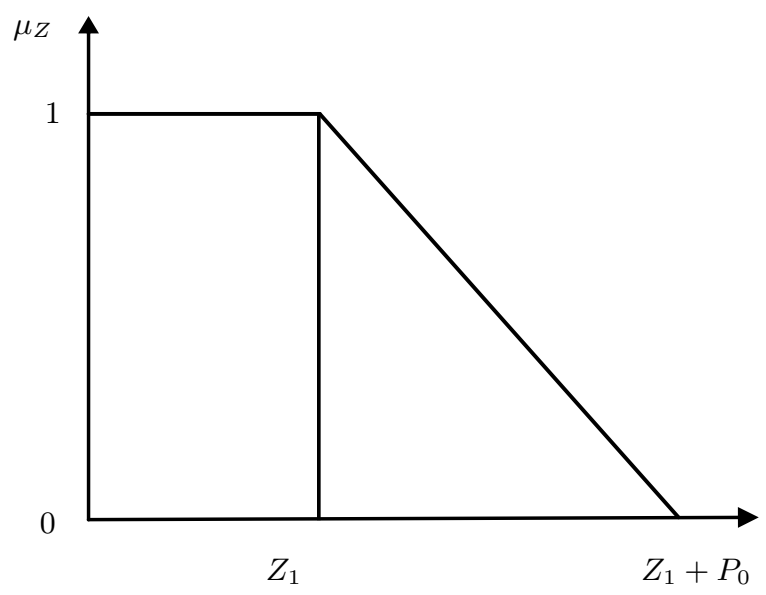

Fig. 1. Membership function for the Problem objective

Membership function for upper bound of annual working-hour constraint

$$
\mu_{U_{i}}(x)= \begin{cases}1 & \text { if } \sum_{t \in T} Y_{i t} \leqslant U_{i} \\ 1+\frac{\left(U_{i}-\sum_{t \in T} Y_{i t}\right)}{P_{1}} & \text { if } U_{i}<\sum_{t \in T} Y_{i t} \leqslant U_{i}+P_{1} \\ 0 & \text { if } U_{i}+P_{1}<\sum_{t \in T} Y_{i t}\end{cases}
$$

where $U_{i} \in\left[U_{i}, U_{i}+P_{1}\right]$ denotes imprecise lower and upper bounds for the fuzzy constraint. $P_{1}$ is the tolerance level that the decision-maker can tolerate in the accomplishment of the fuzzy constraint. 


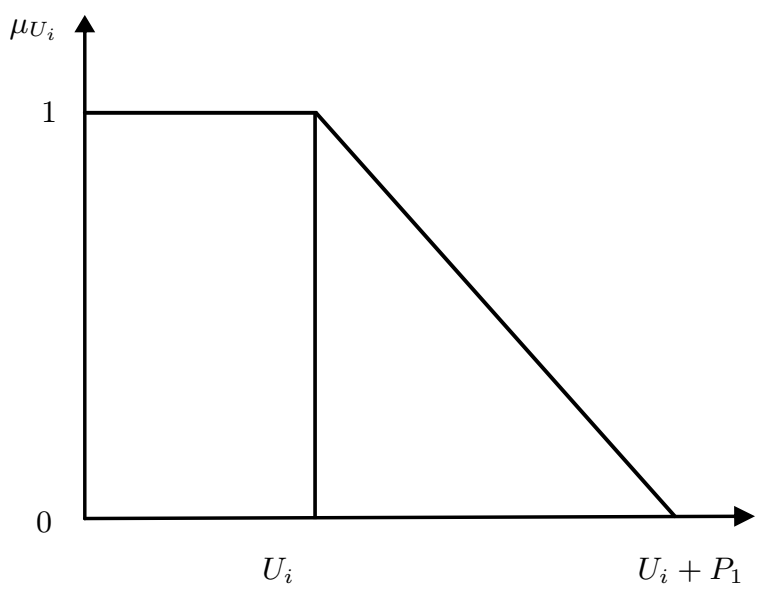

Fig. 2. Membership function for upper bound of annual working-hour constraint

Membership function for lower bound of annual working-hour constraint

$$
\mu_{L_{i}}(x)= \begin{cases}1 & \text { if } L_{i} \leqslant \sum_{t \in T} Y_{i t} \\ 1-\frac{\left(L_{i}-\sum_{t \in T} Y_{i t}\right)}{P_{2}} & \text { if } L_{i}-P_{2} \leqslant \sum_{t \in T} Y_{i t}<L_{i} \\ 0 & \text { if } \sum_{t \in T} Y_{i t}<L_{i}-P_{2}\end{cases}
$$

where $L_{i} \in\left[L_{i}-P_{2}, L_{i}\right]$ denotes imprecise lower and upper bounds for the fuzzy constraint. $P_{2}$ is the tolerance level that the decision-maker can tolerate in the accomplishment of the fuzzy constraint.

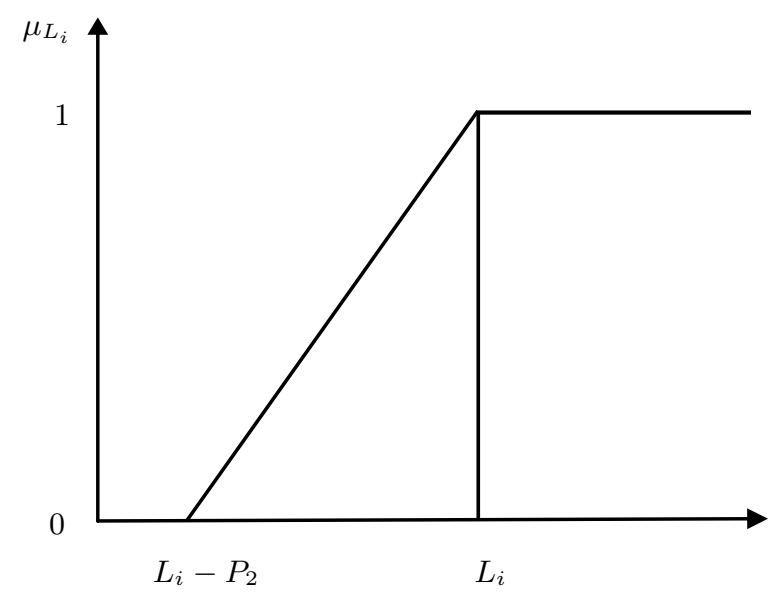

Fig. 3. Membership function for lower bound of annual working-hour constraint 
Membership function for demand constraint

$$
\mu_{D_{j t}}(x)= \begin{cases}1 & \text { if } D_{j t} \leqslant \sum_{i \in I} R E_{i j} \cdot A_{i j t}+S_{j t} \\ 1-\frac{\left(D_{j t}-\sum_{i \in I} R E_{i j} \cdot A_{i j t}-S_{j t}\right)}{P_{3}} & \text { if } D_{j t}-P_{3} \leqslant \\ & \leqslant \sum_{i \in I} R E_{i j} \cdot A_{i j t}+S_{j t}<D_{j t} \\ 0 & \text { if } \sum_{i \in I} R E_{i j} \cdot A_{i j t}+S_{j t}< \\ & <D_{j t}-P_{3}\end{cases}
$$

where demand $D_{j t} \in\left[D_{j t}-P_{3}, D_{j t}\right]$ denotes imprecise lower and upper bounds for the fuzzy demand constraint. $P_{3}$ is the tolerance level that the decision-maker can tolerate in the accomplishment of the fuzzy demand constraint.

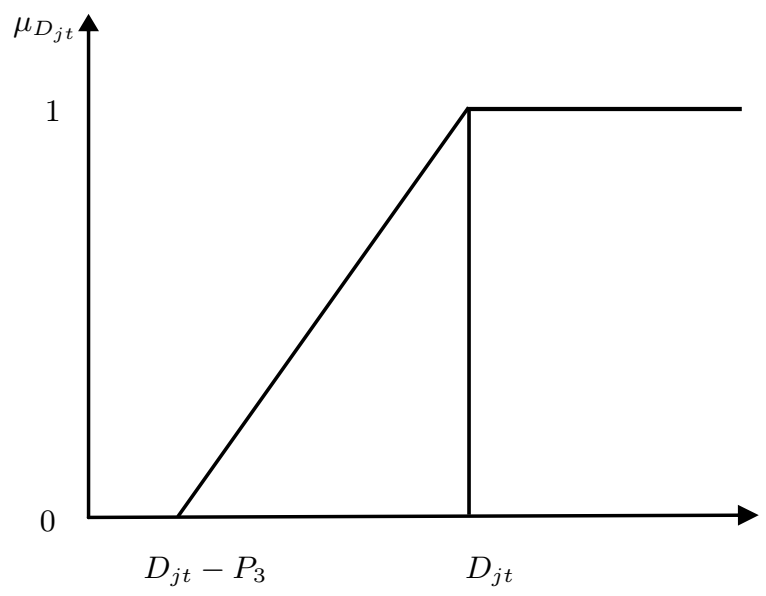

Fig. 4. Membership function for demand constraint

Three FMP approaches are presented to solve the fuzzy annualized hours planning problem.

\section{Fuzzy-min operator model}

Max-min Fuzzy Model (Bellman and Zadeh, 1970) of the AHPP is:

$$
\begin{gathered}
\operatorname{Max}: Z=\lambda \\
\alpha \cdot S+\beta \cdot \sum_{j \in J} \sum_{t \in T} \frac{S_{j t}}{D_{j t}}+\lambda \cdot P_{0} \leqslant Z_{1}+P_{0} \\
S \geqslant \frac{S_{j t}}{D_{j t}} \quad \forall j \in J, t \in T
\end{gathered}
$$




$$
\begin{gathered}
\sum_{t \in T} Y_{i t}+\lambda \cdot P_{1} \leqslant U_{i}+P_{1} \quad \forall i \in I \\
-\sum_{t \in T} Y_{i t}+\lambda \cdot P_{2} \leqslant-\left(L_{i}-P_{2}\right) \quad \forall i \in I \\
L_{i t} \leqslant Y_{i t} \leqslant U_{i t} \quad \forall i \in I, t \in T \\
-\sum_{i \in I} R E_{i j} \cdot A_{i j t}-S_{j t}+\lambda \cdot P_{3} \leqslant-\left(D_{j t}-P_{3}\right) \quad \forall j \in J, t \in T \\
\sum_{t=m-K+1}^{j} Y_{i t} \leqslant h_{K} \cdot K \quad \forall i \in I, m=K \ldots T \\
Y_{i t} \geqslant 0 \text { and } \quad \forall i \in I, t \in T \text { and } \\
\lambda \in[0,1] \\
A_{i j t} \geqslant 0 \quad \forall i \in I, j \in J, t \in T
\end{gathered}
$$

New variable $\lambda \in[0,1]$ shows the level of satisfaction of the least-satisfied constraint.

\section{Fuzzy-com operator model}

Fuzzy AH planning problem model with convex combination of max-operator and min-operator (Zimmermann, 1996):

$$
\begin{gathered}
\text { Max: } \lambda=\gamma \cdot \lambda_{1}+(1-\gamma) \cdot \lambda_{2} \\
\alpha \cdot S+\beta \cdot \sum_{j \in J} \sum_{t \in T} \frac{S_{j t}}{D_{j t}}+\lambda_{1} \cdot P_{0} \leqslant Z_{1}+P_{0} \\
\alpha \cdot S+\beta \cdot \sum_{j \in J} \sum_{t \in T} \frac{S_{j t}}{D_{j t}}+\lambda_{2} \cdot P_{0} \leqslant Z_{1}+P_{0}+M \cdot \pi_{1} \\
S \geqslant \frac{S_{j t}}{D_{j t}} \forall j \in J, t \in T \\
\sum_{t \in T} Y_{i t}+\lambda_{1} \cdot P_{1} \leqslant U_{i}+P_{1} \quad \forall i \in I \\
\sum_{t \in T} Y_{i t}+\lambda_{2} \cdot P_{1} \leqslant U_{i}+P_{1}+M \cdot \pi_{2} \quad \forall i \in I \\
-\sum_{t \in T} Y_{i t}+\lambda_{1} \cdot P_{2} \leqslant-\left(L_{i}-P_{2}\right) \quad \forall i \in I \\
-\sum_{t \in T} Y_{i t}+\lambda_{1} \cdot P_{2} \leqslant-\left(L_{i}-P_{2}\right)+M \cdot \pi_{3} \quad \forall i \in I \\
L_{i t} \leqslant Y_{i t} \leqslant U_{i t} \forall i \in I, t \in T \\
-\sum_{i \in I} R E_{i j} \cdot A_{i j t}-S_{j t}+\lambda_{1} \cdot P_{3} \leqslant-\left(D_{j t}-P_{3}\right) \quad \forall j \in J, t \in T
\end{gathered}
$$




$$
\begin{gathered}
-\sum_{i \in I} R E_{i j} \cdot A_{i j t}-S_{j t}+\lambda_{2} \cdot P_{3} \leqslant-\left(D_{j t}-P_{3}\right)+M \cdot \pi_{4} \quad \forall j \in J, t \in T \\
\sum_{t=m-K+1}^{j} Y_{i t} \leqslant h_{K} \cdot K \quad \forall i \in I, m=K \ldots T \\
\sum_{f=1}^{m} \pi_{f} \leqslant m-1 \\
Y_{i t} \geqslant 0 \text { and } \forall i \in I, t \in T \text { and } \\
\lambda_{1}, \lambda_{2} \in[0,1] \\
A_{i j t} \geqslant 0 \quad \forall i \in I, j \in J, t \in T \\
\pi_{f} \in 0,1, f=1 \ldots m(m=4 \quad \text { fuzzy constraints })
\end{gathered}
$$

Here, $M$ represents a very large number, $\lambda_{1} \in[0,1]$ is the level of satisfaction of the least-satisfied constraint, and $\lambda_{2} \in[0,1]$ is the level of satisfaction of the most-satisfied constraint. The objective is to balance them to maximize total satisfaction. $\gamma \in[0,1]$ is the compensation grade.

For the min operator, the structure of the constraint and the maximization approach are such that the maximum of the minimum of all possible values of $\lambda_{1}$ is selected. For the max operator, the logic of the constraint with binary variable $\pi$ and the maximization approach is to select the level of satisfaction of the most-satisfied constraint.

\section{Fuzzy-and operator model}

Werner's (1987) fuzzy model:

$$
\begin{gathered}
\text { Max: } Z=\lambda+(1-\gamma) \cdot\left(\lambda_{1}+\lambda_{2}+\lambda_{3}+\lambda_{4}\right) / 4 \\
\alpha \cdot S+\beta \cdot \sum_{j \in J} \sum_{t \in T} \frac{S_{j t}}{D_{j t}}+\left(\lambda+\lambda_{1}\right) \cdot P_{0} \leqslant Z_{1}+P_{0} \\
\left(\lambda+\lambda_{1}\right) \leqslant 1 \\
\left(\lambda+\lambda_{2}\right) \leqslant 1 \\
\left(\lambda+\lambda_{3}\right) \leqslant 1 \\
\left(\lambda+\lambda_{4}\right) \leqslant 1 \\
S \geqslant \frac{S_{j t}}{D_{j t}} \forall j \in J, t \in T \\
\sum_{t \in T} Y_{i t}+\left(\lambda+\lambda_{2}\right) \cdot P_{1} \leqslant U_{i}+P_{1} \quad \forall i \in I \\
-\sum_{t \in T} Y_{i t}+\left(\lambda+\lambda_{3}\right) \cdot P_{2} \leqslant-\left(L_{i}-P_{2}\right) \quad \forall i \in I \\
L_{i t} \leqslant Y_{i t} \leqslant U_{i t} \forall i \in I, t \in T
\end{gathered}
$$




$$
\begin{gathered}
-\sum_{i \in I} R E_{i j} \cdot A_{i j t}-S_{j t}+\left(\lambda+\lambda_{4}\right) \cdot P_{3} \leqslant-\left(D_{j t}-P_{3}\right) \quad \forall j \in J, t \in T \\
\sum_{t=m-K+1}^{j} Y_{i t} \leqslant h_{K} \cdot K \quad \forall i \in I, m=K \ldots T \\
Y_{i t} \geqslant 0 \quad \forall i \in I, t \in T \text { and } \\
\lambda, \lambda_{1}, \lambda_{2}, \lambda_{3}, \lambda_{4} \in[0,1] \\
A_{i j t} \geqslant 0 \quad \forall i \in I, j \in J, t \in T
\end{gathered}
$$

$\lambda, \lambda_{1}, \lambda_{2}, \lambda_{3}$, and $\lambda_{4}$ are the levels of satisfaction of the constraints. The objective is to obtain a balance between these to maximize the total satisfaction level. $\gamma \in[0,1]$ is the compensation grade.

In these above models, $\left[Z_{1}, Z_{1}+P_{0}\right]$ is the interval of tolerance for the objective function; i.e., the weighted sum of the maximum relative capacity shortage and average of the all of the relative capacity shortages, $\left[U_{i}, U_{i}+P_{1}\right]$ is the interval of tolerance for the upper limit of the annual working hours for worker $i,\left[L_{i}-P_{2}, L_{i}\right]$ is the interval of tolerance for the lower limit of the annual working hours for worker $i$, and $\left[D_{j t}-P_{3}, D_{j t}\right]$ is the interval of tolerance for the forecasted demand for task $j$ during week $t$.

\section{Algorithm for solution approach of the Annualized Hours Planning Problem with flexible constraints}

The algorithm can be summarized in the following steps:

Step 1. Construct the conventional (crisp) annualized hours planning problem (AHPP) formulation.

Step 2. Solve the Crisp problem and obtain the deterministic solution.

Step 3. Define the membership function of each fuzzy constraint; i.e., objective function, annual upper limit constraint, annual lower limit constraint, and demand constraint.

Step 4. Construct the fuzzy formulation of the AHPP for the three aggregation operators fuzzy-min, fuzzy-com, and fuzzy-and using the membership functions defined in Step 3 and $\gamma=0-0.9$.

Step 5. Solve the fuzzy models and stop.

Step 6. Present the solution to the decision-maker to choose best solution for different values of $\gamma$.

\section{EXPERIMENTAL STUDY}

To show the applicability and decision aspects of our proposed model, a workforce planning problem of a small automotive company is presented. A hypothetical problem is considered that represents a typical workforce-planning situation of an automotive company. For this study, a planning horizon of 52 weeks $(T)$ is considered. An illustrative working-hour demand for the manufacturing of two products $(J)$ wiper motor and starter motor is given for the three different demand patterns presented in Figure 5. 

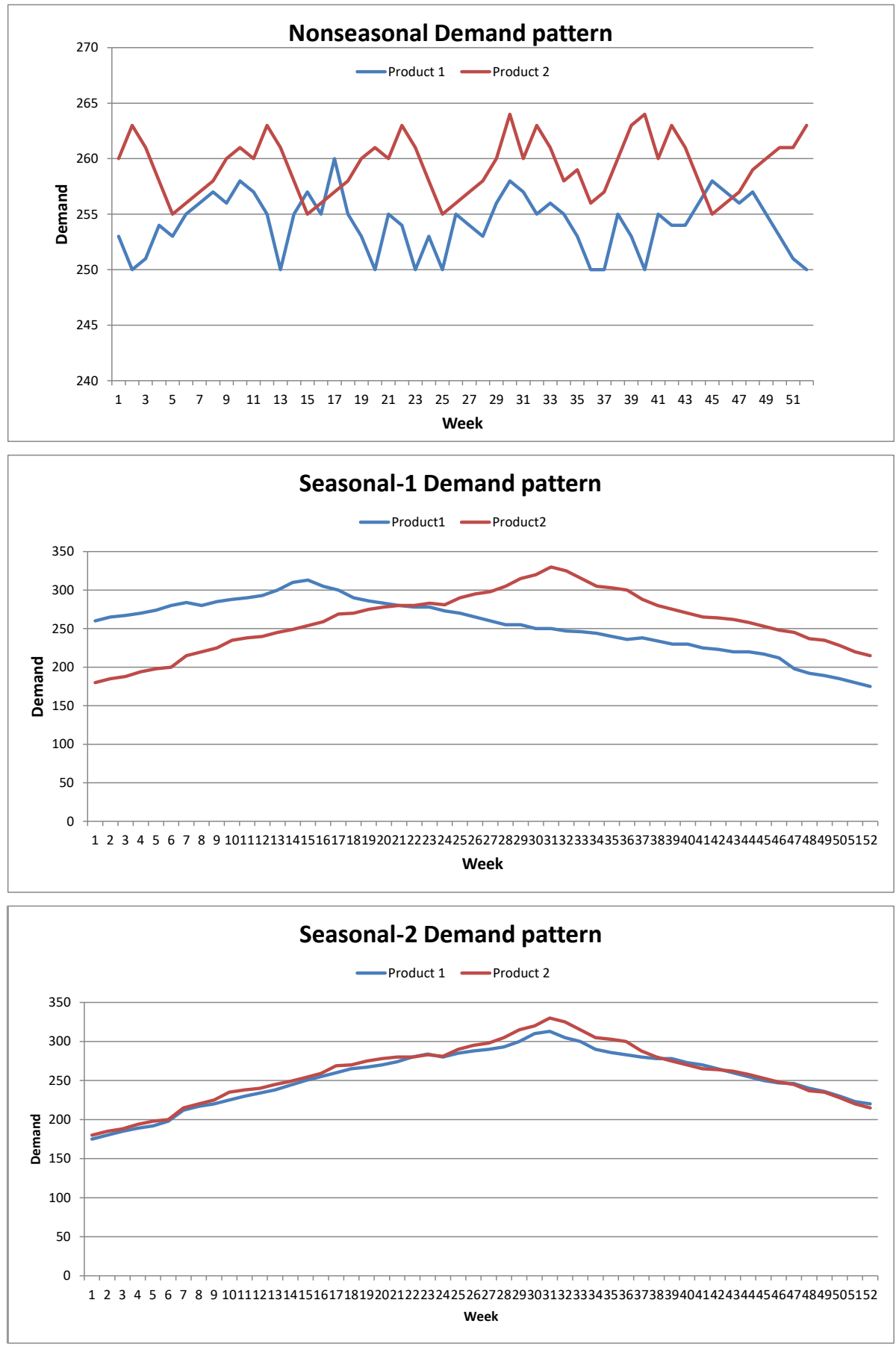

Fig. 5. Demand patterns 
A non-seasonal pattern with constant disturbance in working-hour demand for both products. Here, We considered the Seasonal-1 pattern with a single peak of working-hour demand of products in different period of the year and Seasonal-2 corresponds to a single peak demand during the same period of the year for both products. The weekly working time for each staff member must be between 35 hours $\left(L_{i t}\right)$ and 50 hours $\left(U_{i t}\right)$. The workers are also contracted for 2010 hours $\left(L_{i}\right)$ on an annualized hours basis and (including overtime) a maximum of 2310 hours $\left(U_{i}\right)$. The staff size of 10 workers is considered with respective relative efficiencies for each product on a scale of 1 . There are two categories of workers, where $70 \%$ of the total number of workers have a relative efficiency of 1 for product 1 (wiper motor) and 0.9 for product 2 (starter motor), and the remaining $30 \%$ have a relative efficiency of 0 for product 1 and 1 for product 2 .

The fuzziness is considered in the objective function, annual upper limit constraint, annual lower limit constraint, and demand constraint. The fuzziness is defined by the tolerance interval. The parameters $\left(P_{0}, P_{1}, P_{2}, P_{3}\right)$ required by the fuzzy models are estimated from the resulting solution of the deterministic problem and by the decisionmaker (DM). Here, for this problem, the tolerance level (i.e., $P_{1}, P_{2}, P_{3}$ ) for the fuzzy annual upper limit constraint, annual lower limit constraint, and demand constraint is 100, 200, and 200 hours, respectively. For the fuzzy objective function constraint, the interval of tolerance is $\left[Z_{1}, Z_{1}+P_{0}\right]$, where $Z_{1}=0.1$ and $P_{0}$ for $I=10$ is estimated as 0.0634 for the non-seasonal pattern, whereas for seasonal 1 and seasonal 2 , it is 0.1388 and 0.1872 , respectively. The weights for the maximum relative capacity shortage $(\alpha)$ and sum of weekly relative capacity shortages $(\beta)$ are also assigned by the decisionmaker. Here, they are assigned as $\alpha=0.99$ and $\beta=0.01 /$ (total weeks $\times$ total products), respectively. The weight of the maximum relative capacity shortage is significantly larger than the sum of the weekly relative capacity shortages.

The deterministic and fuzzy models described previously are modeled in the AMPL language and solved using a Gurobi solver using the NEOS server online facility provided by Wisconsin Institutes for Discovery at the University of Wisconsin in Madison for solving optimization problems; see Czyzyk et al. (1998), Dolan (2001), Gropp and Mor (1997), and NEOS (2016).

\section{Results and discussion}

The computational experiment is performed to show the effectiveness of the fuzzy model over the deterministic model. For both the deterministic and fuzzy models' fuzzy parameter $(\lambda)$, maximum relative capacity shortage (MRCS), sum of the relative capacity shortage (SRCS), deterministic objective function (OF), and membership grade [i.e., satisfaction level of objective function $\left(\mu_{Z}\right)$ ] of the fuzzy models is calculated and presented in Tables 1 and 2. Two working staff capacity (i.e., 10 and 40 staff members) is examined to show the model effect on computing time. Three aggregation operators have been used, providing satisfactory results. The maximum relative capacity shortage and sum of the relative capacity shortage shows better results in the fuzzy models than in the deterministic model. The decrease in the sum of the relative capacity shortage and maximum relative capacity shortage gives an increase in the service level by minimizing the objective function. 
Table 1. Solution Results of Crisp, Fuzzy-min and Fuzzy-and models

\begin{tabular}{|c|c|c|c|c|c|c|c|c|c|c|c|c|c|}
\hline \multirow{3}{*}{\multicolumn{2}{|c|}{$I=10$}} & \multirow{3}{*}{ Crisp } & \multirow{3}{*}{ Fuzzy-min } & \multicolumn{10}{|c|}{ Fuzzy-and } \\
\hline & & & & \multicolumn{10}{|c|}{$\gamma$} \\
\hline & & & & 0 & 0.1 & 0.2 & 0.3 & 0.4 & 0.5 & 0.6 & 0.7 & 0.8 & 0.9 \\
\hline \multirow{5}{*}{ 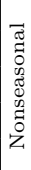 } & $\mathrm{FP}(\lambda)$ & & 0.92 & 0.91 & 0.91 & 0.91 & 0.91 & 0.91 & 0.91 & 0.91 & 0.91 & 0.92 & 0.92 \\
\hline & MRCS & 0.1634 & 0.1047 & 0.1 & 0.1 & 0.1 & 0.1 & 0.1 & 0.1 & 0.1 & 0.1 & 0.1047 & 0.1047 \\
\hline & SRCS & 17.0014 & 10.8981 & 10.4 & 10.4 & 10.4 & 10.4 & 10.4 & 10.4 & 10.4 & 10.4 & 10.8981 & 10.8981 \\
\hline & $\mathrm{OF}$ & 0.1634 & 0.1047 & 0.1 & 0.1 & 0.1 & 0.1 & 0.1 & 0.1 & 0.1 & 0.1 & 0.1047 & 0.1047 \\
\hline & $\mu_{Z}$ & & 0.9244 & 1 & 1 & 1 & 1 & 1 & 1 & 1 & 1 & 0.92 & 0.92 \\
\hline \multirow{5}{*}{ 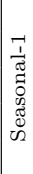 } & $\mathrm{FP}$ & & 0.8358 & 0.80 & 0.80 & 0.80 & 0.80 & 0.80 & 0.80 & 0.8358 & 0.8358 & 0.8358 & 0.8358 \\
\hline & MRCS & 0.2388 & 0.1227 & 0.1 & 0.1 & 0.1 & 0.1 & 0.1 & 0.1 & 0.1227 & 0.1227 & 0.1227 & 0.1227 \\
\hline & SRCS & 24.8405 & 12.7702 & 10.4 & 10.4 & 10.4 & 10.4 & 10.4 & 10.4 & 12.7702 & 12.7702 & 12.7702 & 12.7702 \\
\hline & $\mathrm{OF}$ & 0.2388 & 0.1227 & 0.1 & 0.1 & 0.1 & 0.1 & 0.1 & 0.1 & 0.1227 & 0.1227 & 0.1227 & 0.1227 \\
\hline & $\mu_{Z}$ & & 0.8358 & 1 & 1 & 1 & 1 & 1 & 1 & 0.8358 & 0.8358 & 0.8358 & 0.8358 \\
\hline \multirow{5}{*}{ 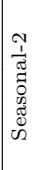 } & FP & & 0.7794 & 0.7170 & 0.7170 & 0.7170 & 0.7170 & 0.7794 & 0.7794 & 0.7794 & 0.7794 & 0.7794 & 0.7794 \\
\hline & MRCS & 0.2872 & 0.1412 & 0.1 & 0.1 & 0.1 & 0.1 & 0.1412 & 0.1412 & 0.1412 & 0.1412 & 0.1412 & 0.1412 \\
\hline & SRCS & 29.8775 & 14.6944 & 10.4 & 10.4 & 10.4 & 10.4 & 14.6944 & 14.6944 & 14.6944 & 14.6944 & 14.6944 & 14.6944 \\
\hline & $\mathrm{OF}$ & 0.2872 & 0.1412 & 0.1 & 0.1 & 0.1 & 0.1 & 0.1412 & 0.1412 & 0.1412 & 0.1412 & 0.1412 & 0.1412 \\
\hline & $\mu_{Z}$ & & 0.7794 & 1 & 1 & 1 & 1 & 0.77 & 0.77 & 0.77 & 0.77 & 0.77 & 0.77 \\
\hline
\end{tabular}

Table 2. Solution Results of Fuzzy-com model

\begin{tabular}{|c|c|c|c|c|c|c|c|c|c|c|c|}
\hline \multirow{3}{*}{\multicolumn{2}{|c|}{$I=10$}} & \multicolumn{10}{|c|}{ Fuzzy-com } \\
\hline & & \multirow{3}{*}{$\begin{array}{l}0 \\
1\end{array}$} & \multirow{3}{*}{$\frac{\mathbf{0 . 1}}{0.99}$} & \multirow{3}{*}{$\frac{\mathbf{0 . 2}}{0.98}$} & \multirow{3}{*}{$\frac{\mathbf{0 . 3}}{0.97}$} & \multicolumn{2}{|c|}{$\gamma$} & \multirow{3}{*}{$\begin{array}{c}\mathbf{0 . 6} \\
0.9546\end{array}$} & \multirow{3}{*}{$\frac{\mathbf{0 . 7}}{0.94}$} & \multirow{3}{*}{$\frac{\mathbf{0 . 8}}{0.93}$} & \multirow{3}{*}{$\frac{\mathbf{0 . 9}}{0.93}$} \\
\hline & & & & & & 0.4 & 0.5 & & & & \\
\hline \multirow{5}{*}{ 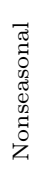 } & $\operatorname{FP}(\lambda)$ & & & & & 0.96 & 0.96 & & & & \\
\hline & MRCS & 0.1634 & 0.1047 & 0.1047 & 0.1047 & 0.1047 & 0.1047 & 0.1047 & 0.1047 & 0.1047 & 0.1047 \\
\hline & SRCS & 16.9936 & 10.8981 & 10.8981 & 10.8981 & 10.8981 & 10.8981 & 10.8981 & 10.8981 & 10.8981 & 10.8981 \\
\hline & OF & 0.1634 & 0.1047 & 0.1047 & 0.1047 & 0.1047 & 0.1047 & 0.1047 & 0.1047 & 0.1047 & 0.1047 \\
\hline & $\mu_{Z}$ & 0 & 0.92 & 0.92 & 0.92 & 0.92 & 0.92 & 0.92 & 0.92 & 0.92 & 0.92 \\
\hline \multirow{5}{*}{ 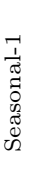 } & FP & 1 & 0.98 & 0.96 & 0.95 & 0.93 & 0.91 & 0.9014 & 0.88 & 0.86 & 0.85 \\
\hline & MRCS & 0.2388 & 0.1227 & 0.1227 & 0.1227 & 0.1227 & 0.1227 & 0.1227 & 0.1227 & 0.1227 & 0.1227 \\
\hline & SRCS & 24.8352 & 12.7702 & 12.7702 & 12.7702 & 12.7702 & 12.7702 & 12.7702 & 12.7702 & 12.7702 & 12.7702 \\
\hline & OF & 0.2388 & 0.1227 & 0.1227 & 0.1227 & 0.1227 & 0.1227 & 0.1227 & 0.1227 & 0.1227 & 0.1227 \\
\hline & $\mu_{Z}$ & 0 & 0.8358 & 0.8358 & 0.8358 & 0.8358 & 0.8358 & 0.8358 & 0.8358 & 0.8358 & 0.8358 \\
\hline \multirow{5}{*}{ 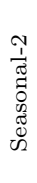 } & FP & 1 & 0.97 & 0.95 & 0.93 & 0.91 & 0.88 & 0.8676 & 0.84 & 0.82 & 0.80 \\
\hline & MRCS & 0.28 & 0.1412 & 0.1412 & 0.1412 & 0.1412 & 0.1412 & 0.1412 & 0.1412 & 0.1412 & 0.1412 \\
\hline & SRCS & 29.86 & 14.6944 & 14.6944 & 14.6944 & 14.6944 & 14.6944 & 14.6944 & 14.6944 & 14.6944 & 14.6944 \\
\hline & OF & 0.28 & 0.1412 & 0.1412 & 0.1412 & 0.1412 & 0.1412 & 0.1412 & 0.1412 & 0.1412 & 0.1412 \\
\hline & $\mu_{Z}$ & 0 & 0.77 & 0.77 & 0.77 & 0.77 & 0.77 & 0.77 & 0.77 & 0.77 & 0.77 \\
\hline
\end{tabular}

A sensitivity analysis is conducted to see the effect of alternative values of the compensation grades for the fuzzy-and and fuzzy-com operator models. The solution for sensitivity analysis gives us alternatives to be selected as best considering the priorities of the decision-maker. For a better understanding, the result data is presented in Figures 6, 7, 8, and 9.

Figures 6 and 7 show that the MRCS and SRCS for the fuzzy-and operator model is less than the fuzzy-com operator model from $\gamma=0-0.9$. 

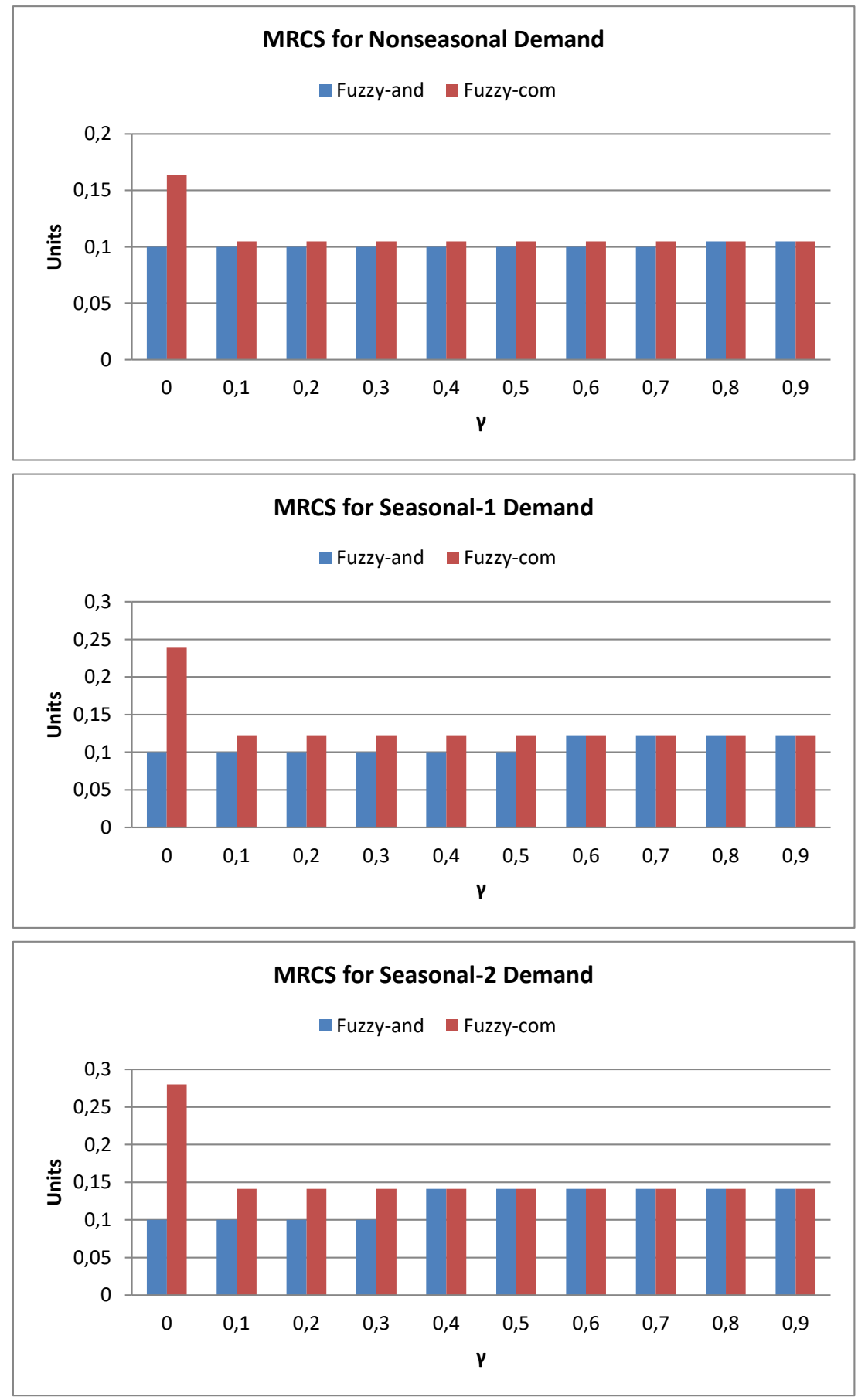

Fig. 6. Maximum relative capacity shortages (MRCS) 

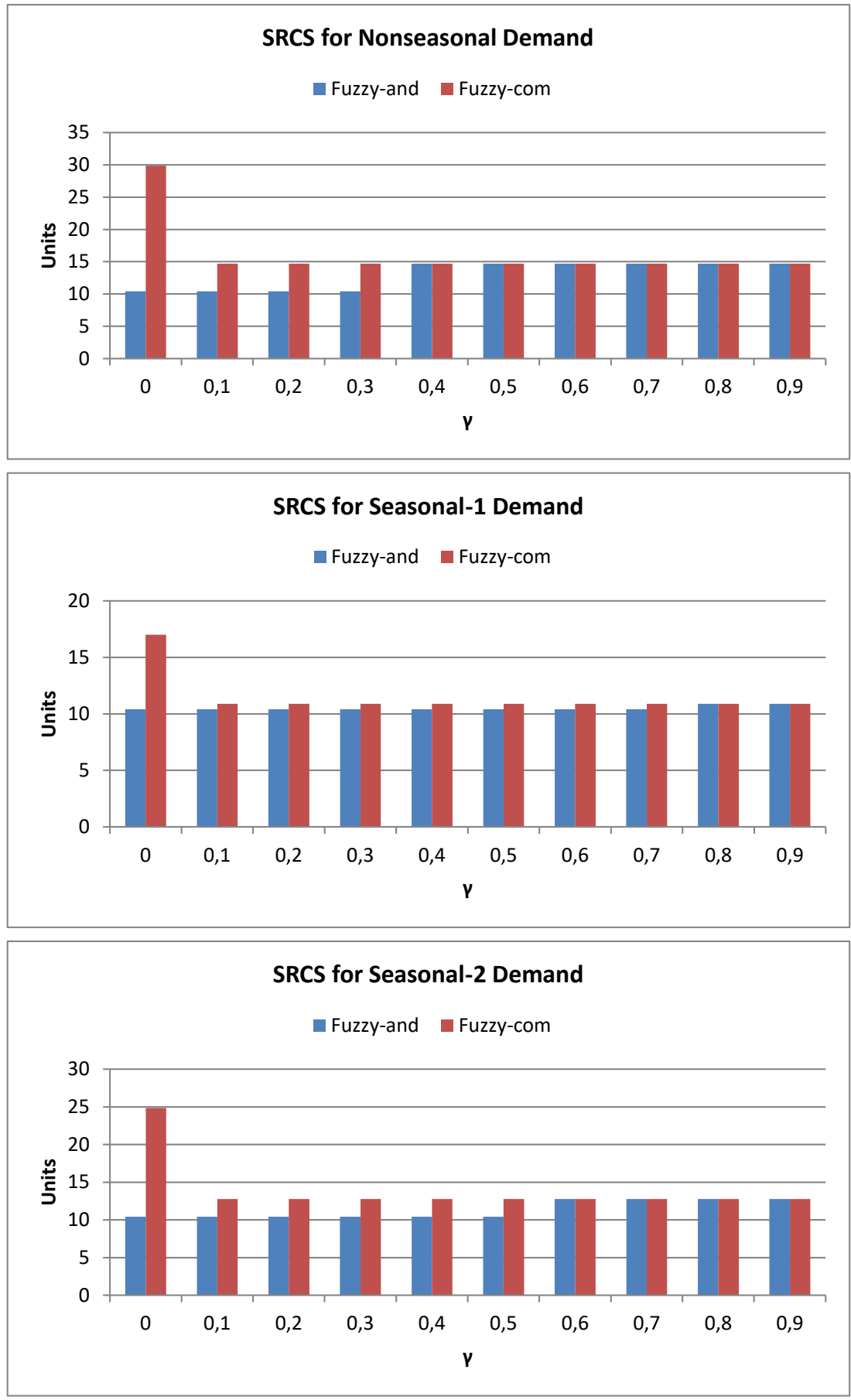

Fig. 7. Sum of relative capacity shortages (SRCS) 

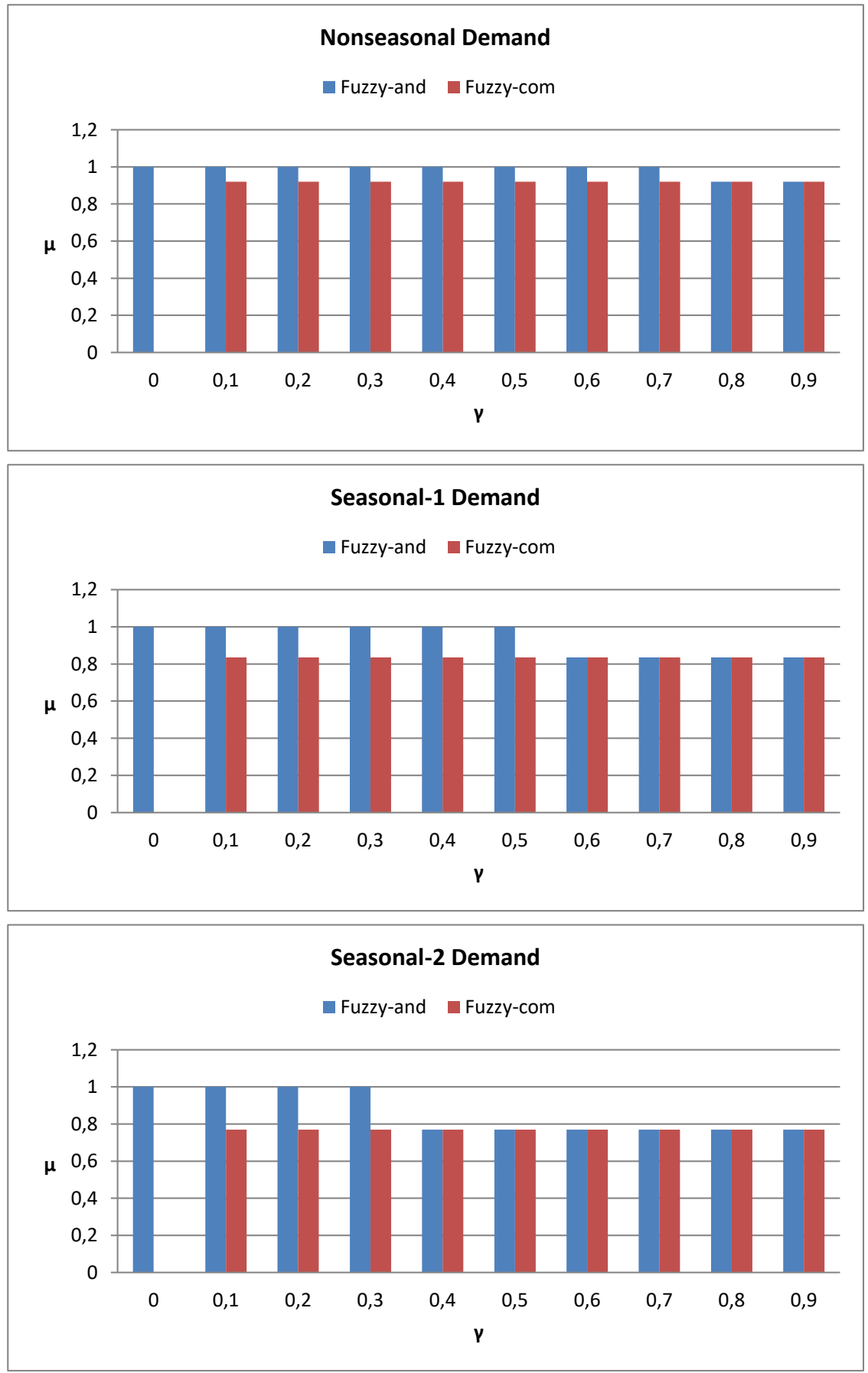

Fig. 8. Satisfaction level $\left(\mu_{z}\right)$ of objective function 

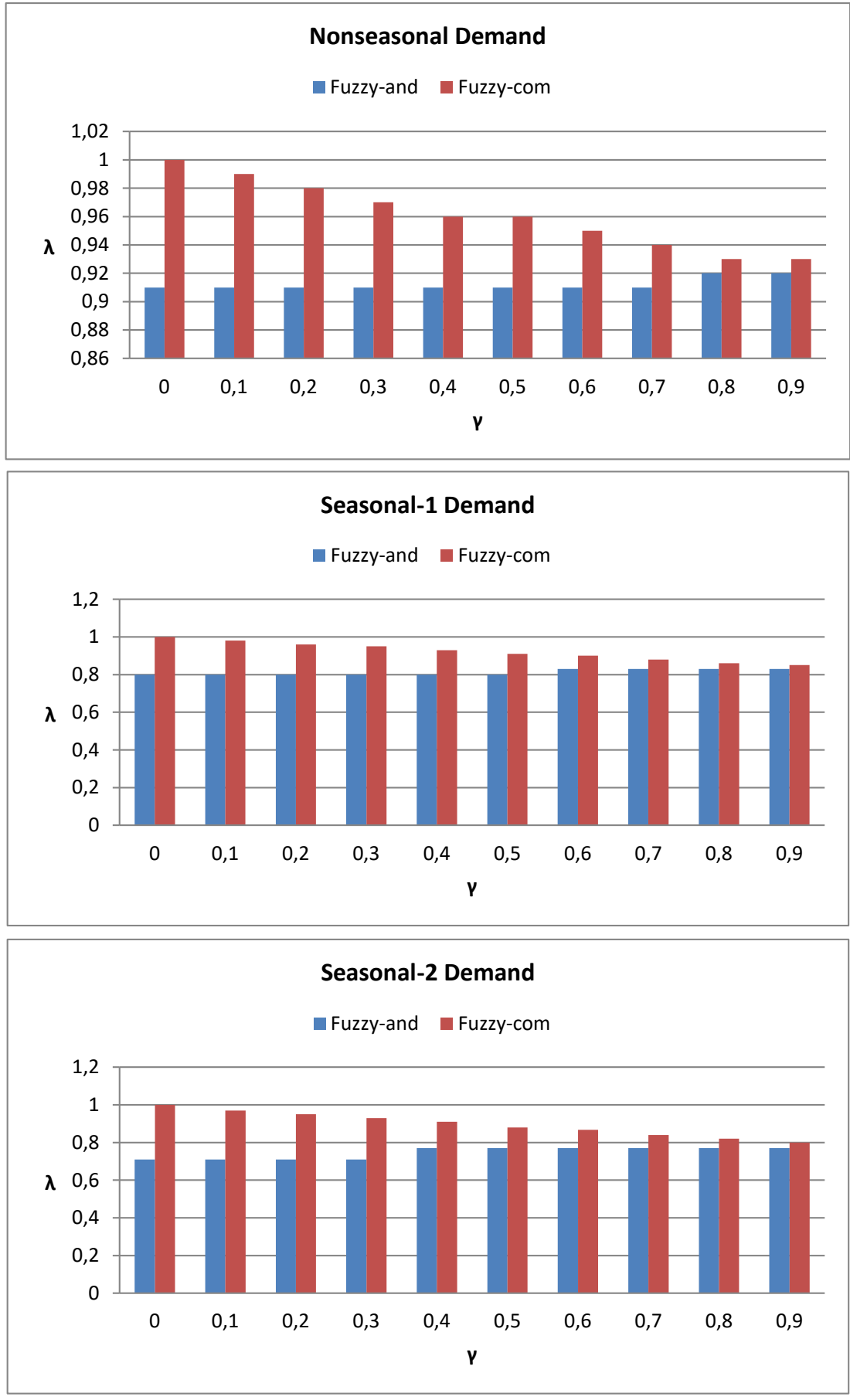

Fig. 9. Level of satisfaction ( $\lambda$ ) of less satisfied constraint 
Figure 8 shows that the level of satisfaction for the objective function is high for the fuzzy-and model than it is for the fuzzy-com model. Although in the fuzzy-and model, the level of satisfaction decreases from $\gamma=0-0.9$, and for fuzzy-com, it remains constant from $\gamma=0.1-0.9$. In Figure 9, level of satisfaction $(\lambda)$ for the least-satisfied constraint is presented. It decreases for the fuzzy-com model in all of the demand patterns, while for the fuzzy-and model, it increases from $\gamma=0-0.9$. If the decision-maker is interested in the satisfaction level of the objective function, MRCS, SRCS, $\mathrm{OF}$, or all together, then the fuzzy-and operator is best for the compensation grade alternatives from $\gamma=0-0.7$ for non-seasonal demand, $\gamma=0-0.5$ for seasonal 1 , and $\gamma=0-0.3$ for the seasonal 2 demand pattern. If the decision-maker is concerned only about fuzzy parameter $(\lambda)$, then fuzzy-com operator is the best one for $\gamma=0.1$. The alternative $\gamma=0$ and 1 correspond to the min operator and simple additive approach, respectively.

Hence, the fuzzy-and operator is the best-overall-solution approach when compared to the other approaches, and it shows better results in the fuzzy models as compared to the deterministic model. For the non-seasonal, seasonal-1, and seasonal-2 demand patterns, there is a difference of $38.80 \%, 58.12 \%$, and $65.18 \%$, respectively, in the values of the objective function of the fuzzy-and and deterministic models. This difference is due to the rigid constraints of the deterministic model. The fuzzy model gives more flexibility to the decision-maker.

The computation time is shown graphically in Figure 10.
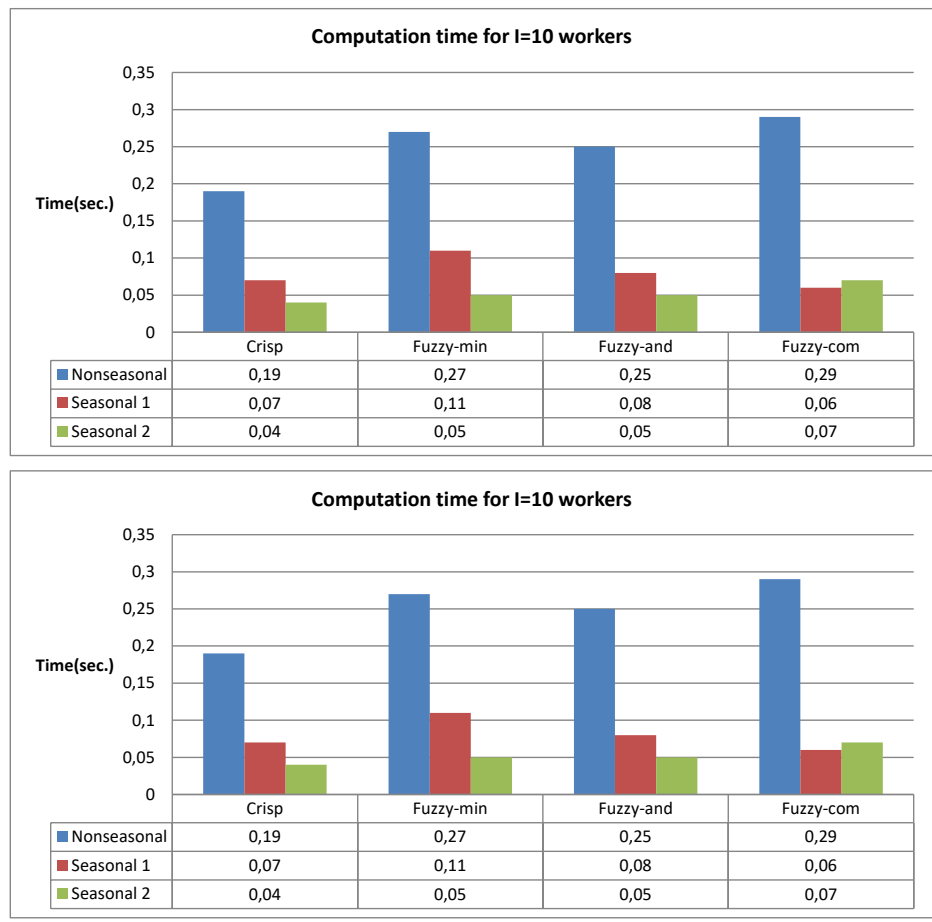

Fig. 10. Solver computation time chart for models with $I=10$ and 40 
The size of the models is given in Table 3. The number of workers increases the size of the model by increasing the number of constraints and variables. CPU time depends on the size of the model due to the larger amount of information stored. The deterministic model requires lower computational effort as compare to the fuzzy models. Among the fuzzy models, the fuzzy-and operator performs better in general. Overall, the model is solved in acceptable time; even an increase in model size from 10 staff members to 40 does not make the computation time unacceptable. The maximum computation time is for the fuzzy-com model for a staff size of 40 during non-seasonal demand.

Table 3. Constraint and variable statistics of models

\begin{tabular}{|l|c|c|c|c|}
\cline { 2 - 5 } \multicolumn{1}{c|}{} & \multicolumn{2}{c|}{$\boldsymbol{I = 1 0}$} & \multicolumn{2}{c|}{$\boldsymbol{I = 4 0}$} \\
\cline { 2 - 5 } \multicolumn{1}{c|}{} & Constraints & Variables & Constraints & Variables \\
\hline Crisp & 1263 & 1666 & 4113 & 6346 \\
Fuzzy-min & 1390 & 1793 & 4300 & 6533 \\
Fuzzy-and & 1394 & 1797 & 4304 & 6537 \\
Fuzzy-com & 1526 & 1808 & 4526 & 6578 \\
\hline
\end{tabular}

\section{CONCLUSION}

In this paper, we integrated a basic model of the annualized hours planning problem with fuzzy uncertainty. The summary of the proposed fuzzy models for the AHPP is presented in Table 4. An AHPP problem with multi tasks and cross-trained workers with respective relative efficiency in three different demand patterns is considered. Previously, the AHPP was solved using deterministic data. We modeled this problem as a fuzzy mathematical programming problem.

In real life, the parameters in the AHPP may not be precisely known. Fuzzy models offer wider flexibility and an efficient option to deal with the uncertainty of real life. These fuzzy models soften the rigidity of the deterministic model by relaxing some of the constraints that use flexible programming.

Three models of the AHPP (Fuzzy-min, Fuzzy-and, and Fuzzy-com) under conditions of uncertainty have been presented using different aggregation operators. Also, a hypothetical experimental study has been done to show the effectiveness of the fuzzy approach. The fuzzy-and operator is found suitable as a best-solution approach when compared to the other approaches, and it shows better results in fuzzy models as compared to the deterministic model. There is a difference of $38.80 \%, 58.12 \%$, and $65.18 \%$ in the values of the objective function of the fuzzy-and and deterministic models for non-seasonal, seasonal-1, and seasonal-2 demand patterns, respectively. This difference is due to the rigidity of the constraints in the deterministic model. The fuzzy model provides more flexibility to the decision-maker.

The computational performance is analyzed for different model sizes and was found to be acceptable. The main contribution of this paper is the application of flexible 
programming in the AHPP, which is a better option when dealing with uncertainty. In the future, the work may be extended to multi-objective annualized hours planning problems, considering fuzzy and probabilistic uncertainty, learning curves, and human factors like willingness, efficiency, etc. These extensions may help to provide better decision-making in real-life scenarios.

Table 4. Summary of Fuzzy AHPP Models

\begin{tabular}{|c|c|}
\hline Source of Fuzziness & $\begin{array}{l}\text { (1) Aspiration of objective function } \\
\text { (2) Lower limit of Annual working hour constraint i.e. } \\
\text { Minimum of contracted working hours of staff } \\
\text { (3) Upper limit of Annual working hour constraint i.e. } \\
\text { Maximum of working hours of staff including overtime } \\
\text { (4) Demand of working hours }\end{array}$ \\
\hline Objective & $\begin{array}{l}\text { Weighted sum of (1) maximum relative capacity shortage } \\
\text { and (2) average relative capacity shortage for the whole } \\
\text { planning period with } \alpha \text { and } \beta \text { as their associated weights. }\end{array}$ \\
\hline Membership function & Linear membership function \\
\hline Solution approach & $\begin{array}{l}\text { (1) Max-min operator (Bellman and Zadeh, 1970) } \\
\text { (2) Convex combination of min-operator and max-operator } \\
\text { (Zimmermann, 1996) } \\
\text { (3) Fuzzy-and operator (Werner's, 1987) }\end{array}$ \\
\hline Software used & $\begin{array}{l}\text { NEOS Server: State-of-the-Art Solvers for Numerical } \\
\text { Optimization (NEOS, 2016) } \\
\text { Coding: AMPL } \\
\text { Solver: Gurobi }\end{array}$ \\
\hline
\end{tabular}

\section{REFERENCES}

Azmat, C.S., Widmer, M., 2004. A case study of single shift planning and scheduling under annualized hours: A simple three-step approach. European Journal of Operational Research, 153(1), pp. 148-175.

Azmat, C.S., Hürlimann, T., Widmer, M., 2004. Mixed integer programming to schedule a single-shift workforce under annualized hours. Annals of Operations Research, 128(1-4), pp. 199-215.

Bellman, R.E., Zadeh, L.A., 1970. Decision making in a fuzzy environment. Management Sciences, 17, pp. 141-164.

Cadenas, J.M., Verdegay, J.L., 2006. A primer on fuzzy optimization models and methods. Iranian Journal of Fuzzy Systems, 3(1), pp. 1-21.

Campbell, G.M., Diaby, M., 2002. Development and evaluation of an assignment heuristic for allocation cross-trained workers. European Journal of Operational Research, 138, pp. 9-20. 
Corominas, A., Pastor, R., 2000. Manpower planning and scheduling in services with seasonal demand. In: Machuca, J.A.D., Mandakovic, T., (eds.), Proceedings of the I World Conference on Production and Operations Management, August $27^{\text {th }}-$ September $1^{\text {st }}$, 2000, Sevilla, Spain.

Corominas, A., Pastor, R., 2010. Replanning working time under annualised working hours. International Journal of Production Research, 48(5), pp. 1493-1515.

Corominas, A., Lusa, A., Pastor, R., 2002. Using MILP to plan annualised working hours. The Journal of the Operational Research Society, 53(10), pp. 1101-1108.

Corominas, A., Lusa, A., Pastor, R., 2004. Planning annualised hours with a finite set of weekly working hours and joint holidays. Annals of Operations Research, 128(1-4), pp. 217-233.

Corominas, A., Lusa, A., Pastor, R., 2005. Annualised hours a real flexibility tool. OR Insight, 18(1), pp. 10-14.

Corominas, A., Lusa, A., Pastor, R., 2007a. Planning production and working time within an annualised hours scheme framework, Annals of Operations Research, 155(1), pp. 5-23.

Corominas, A., Lusa, A., Pastor, R., 2007b. Using a MILP model to establish a framework for an annualised hours agreement. European Journal of Operational Research, 177(3), pp. $1495-1506$.

Corominas, A., Lusa, A., Olivella, J., 2012. A detailed workforce planning model including non-linear dependence of capacity on the size of the staff and cash management. European Journal of Operational Research, 216(2), pp. 445-458.

Czyzyk, J., Mesnier, M.P., Moré, J.J., 1998. The NEOS Server. IEEE Journal on Computational Science and Engineering, 5(3), pp. 68-75.

Dolan, E., 2001. The NEOS Server 4.0 Administrative Guide. Technical Memorandum ANL/MCSTM250, Mathematics and Computer Science Division, Argonne National Laboratory.

Filho, E.V.G., Marçola, J.A., 2001. Annualized hours as a capacity planning tool in maketo-order or assemble-to-order environment: an agricultural implements company case. Production Planning and Control, 12(4), pp. 388-398.

Grabot, B., Letouzey, A., 2000. Short-term manpower management in manufacturing systems: new requirements and DSS prototyping. Computers in Industry, 43(1), pp. 11-29.

Gropp, W., Moré, J.J., 1997. Optimization Environments and the NEOS Server. In: Buhmann, M.D., Iserles, A. (eds.), Approximation Theory and Optimization, Cambridge University Press, pp. 167-182.

Hertz, A., Lahrichi, N., Widmer, M., 2010. A flexible MILP model for multiple-shift workforce planning under annualized hour. European Journal of Operational Research, 200(3), pp. 860-873.

Hung, R., 1999a. A multiple-shift workforce scheduling model under annualized hours. Naval Research Logistics, 46(6), pp. 726-736.

Hung, R., 1999b. Scheduling a workforce under annualized hours. International Journal of Production Research, 37(11), pp. 2419-2427.

Itoh, T., Ishii, H., Nanseki, T., 2003. A model of crop planning under uncertainty in agricultural management. International Journal of Production Economics, 81-82, pp. 555-558.

Jiafu, T., Dingwei, W., Fung, R.Y.K., Yung, K.L., 2004. Understanding of fuzzy optimization: theories and methods. Journal of Systems Science and Complexity, 17(1), pp. 117-136. 
Lai, Y.J., Hwang, C.L., 1992. Fuzzy Mathematical Programming, Lecture Notes in Economics and Mathematical Systems 394, Springer-Verlag, Berlin.

Lusa, A., Pastor, R., 2011. Planning working time accounts under demand uncertainty. Computers \& Operations Research, 38(2), pp. 517-524.

Lusa, A., Corominas, A., Muñoz, N., 2008a. A multistage scenario optimisation procedure to plan annualised working hours under demand uncertainty. International Journal of Production Economics, 113(2), pp. 957-968.

Lusa, A., Corominas, A., Olivella, J., Pastor, R., 2009. Production planning under a working time accounts scheme. International Journal of Production Research, 47(13), pp. 3435-3451.

McMeekin, J., 1995. Why Tesco's new composite distribution needed annual hours. International Journal of Retail and Distribution Management, 23(9), pp. 36-38.

Miller, W.A., Leung, L.C., Azhar, T.M., Sargent, S., 1997. Fuzzy production planning model for fresh tomato packing. International Journal of Production Economics, 53(3), pp. 227-238.

NEOS Server: State-of-the-Art Solvers for Numerical Optimization, http://www . neos-server.org/neos/, accessed on 2016 June 21.

Official governmental site on the 35-hour workweek, http://travail-emploi.gouv.fr/, accessed on 2016 June 21.

Pendharkar, P.C., 1997. A fuzzy linear programming model for production planning in coal mines. Computers \& Operations Research, 24, pp. 1141-1149.

Rabbani, M., Jolai, F., Manavizadeh, N., Radmehr, F., Javadi, B., 2012. Solving a bi-objective cell formation problem with stochastic production quantities by a two-phase fuzzy linear programming approach. International Journal of Industrial Engineering Computations, 58, pp. 709-722.

Rodriguez, M., 2003. Flexible working patterns using annualised hours. Work Study, 52(3), pp. $145-149$.

Sanderson, T., 2016. Improving Productivity through workforce agility. Available at: http://www.smart-workforce.com/resource/uploads/publications/thomas_ sanderson.pdf, accessed on 2016 June 21.

Selim, H., Ozkarahan, I., 2008. A Supply chain distribution network design model: An interactive fuzzy goal programming-based solution approach. International Journal of Industrial Engineering Computations, 36, pp. 401-418.

Sureshkumar, M.R., Pillai, V.M., 2012. Planning annualized hours when spike in demand exists. International Journal of Industrial Engineering Computations, 3, pp. 313-320.

Sureshkumar, M.R., Pillai, V.M., 2013. An efficient method to reduce relative capacity shortage using annualized hours planning. The International Journal of Advanced Manufacturing Technology, 65, pp. 571-580.

Tsai, C.-C., Chu, C.-H., Barta, T.A., 1997. Modeling and analysis of a manufacturing cell formation problem with fuzzy mixed-integer programming. IIE Transactions, 29(7), pp. 533-547.

Ull Hasan, M.G., Ali, I., Hasan, S.S., 2016. Annualized hours planning with fuzzy demand constraint. ProbStat Forum, 09, pp. 50-56.

Van den Hurk, H., 2007. Arbeidsvoorwaarden in 100 vragen: voor OR'en en HR-medewerkers, Kluwerm, Alphen aan den Rijn, The Netherlands (in Dutch). 
Van der Veen, E., Boucherie, R.J., Van Ommeren, J.C.W., 2012. Optimal staffing under an annualized hours regime using cross-entropy optimization, Memorandum 1982, Department of Applied Mathematics, University of Twente, Enschede.

Van der Veen, E., Hans, E.W., Veltman, B., Berrevoets, L.M., Berden H.J.J.M., 2014. A case study of cost-efficient staffing under annualized hours. Health Care Management Science, 18(3), pp. 279-288.

Werner, B., 1987. An interactive fuzzy programming system. Fuzzy Sets and Systems, 23, pp. 131-147.

Wikipedia, 2016, 35-hours workweek, [online] Available at https://en.wikipedia.org/wiki/ 35-hourworkweek, accessed on 2016 June 21.

Zadeh, L.A., 1965. Fuzzy sets. Information and Control, 8, pp. 338-353.

Zimmermann, H.J., 1976. Description and optimization of fuzzy systems. International Journal of General Systems, 2, pp. 209-215.

Zimmermann, H.J., 1996. Fuzzy set theory and its applications (3rd ed.), Boston, Kluwer Academic Publishers. 